\title{
Antimigraine drug sumatriptan increases blood flow velocity in large cerebral arteries during migraine attacks
}

\author{
J.F.V. Caekebeke, MD; M.D. Ferrari, MD; C.P. Zwetsloot, MD; J. Jansen; and P.R. Saxena, MD, PhD
}

\begin{abstract}
Article abstract-Sumatriptan, a novel selective 5-hydroxytryptamine ${ }_{1 \mathrm{~d}}\left(5-\mathrm{HT}_{1 \mathrm{~d}}\right)$ receptor agonist, which is highly effective in the acute treatment of migraine attacks, blocks dural neurogenic plasma extravasation and constricts cranial blood vessels in animal experiments. We measured intra- and extracranial blood flow velocities (BFV) with a transcranial Doppler device in 67 patients during a spontaneous migraine attack, before and after treatment with 3 $\mathrm{mg}$ or $6 \mathrm{mg}$ subcutaneous sumatriptan or placebo. Sumatriptan, but not placebo, significantly increased BFV $(\mathrm{cm} / \mathrm{sec})$ in the internal carotid and middle cerebral arteries on both sides, without detectably changing the BFV in the common and external carotid arteries. The rise in BFV increased with the dose of sumatriptan, parallel to an increase in proportion of patients improved. There were no significant changes in heart rate, blood pressure, or respiratory frequency after treatment with sumatriptan. The increase in BFV probably reflects vasoconstriction of the large basal intracranial arteries, which may be a mechanism for the antimigraine action of sumatriptan.
\end{abstract}

NEUROLOGY 1992;42:1522-1526

Sumatriptan is a novel selective 5-hydroxytryptamine $_{1 d}\left(5-\mathrm{HT}_{1 \mathrm{~d}}\right)$-like receptor agonist, ${ }^{1,2}$ highly effective in the acute treatment of migraine attacks. ${ }^{3}$ Following subcutaneous (sc) injection with $6 \mathrm{mg}$ sumatriptan, nearly $90 \%$ of the patients improve within 2 hours. ${ }^{3}$

Sumatriptan shows a remarkable selective pharmacologic profile. In animal experiments, it has a marked vasoconstrictor effect on cephalic arteriovenous anastomoses, redirecting the blood flow to the capillary bed.,4-6 Sumatriptan also blocks neurogenic plasma extravasation from blood vessels in the dura mater of the rat, presumably by presynaptic inhibition of vasoactive neuropeptide release. ${ }^{2,7}$

In humans, little is known about the pharmacologic actions of sumatriptan and its actual mechanism of action in migraine. A vasoconstrictor effect would be compatible with the vascular hypothesis for migraine, suggesting that vasodilatation of intracranial blood vessels is crucial for the development of the migraine headache. ${ }^{8,9}$ A neuronal effect would support the neurovascular hypothesis that the migraine headache is not due to vasodilatation but is caused by an axonal reflex mechanism in the trigeminovascular system..$^{10}$ Both mechanisms may be involved. 5

The transcranial Doppler technique is a nonin- vasive and relatively easy technique to measure changes in blood flow velocity (BFV). ${ }^{11}$ With constant blood flow, increase of $\mathrm{BFV}$ indicates vasoconstriction, whereas decrease of $\mathrm{BFV}$ indicates vasodilatation.

We therefore investigated whether sumatriptan changes the $\mathrm{BFV}$ during spontaneous migraine attacks in the common carotid (CCA), external carotid (ECA), internal carotid (ICA), and middle cerebral (MCA) arteries. We also studied whether this effect would be different at the headache and nonheadache sides.

Methods. This study was performed as part of two consecutive, double-blind, placebo-controlled, in-hospital clinical trials in which patients were treated during spontaneous migraine attacks with various doses of sc sumatriptan. In the first trial, patients were treated with placebo or 1,2 , or $3 \mathrm{mg}$ sc sumatriptan. If the patient had not improved sufficiently after 30 minutes, a second sc injection with $3 \mathrm{mg}$ sumatriptan was given. ${ }^{12}$ In the second trial, patients received placebo or $6 \mathrm{mg}$ sc sumatriptan. If the patient had not improved sufficiently after 60 minutes, a second sc injection with $6 \mathrm{mg}$ sumatriptan was given. ${ }^{3}$

We measured the BFV in the CCA, ECA, ICA, and MCA on both sides of the head, just before and 30 minutes after the final sc injection of sumatriptan with an

From the Department of Neurology (Drs. Caekebeke, Ferrari, and Zwetsloot, and J. Jansen), University Hospital, Leiden; the Department of Pharmacology (Dr. Saxena), Erasmus University, Rotterdam; and The Dutch Migraine Research Group (Drs. Ferrari and Saxena), The Netherlands.

Received October 22, 1991. Accepted for publication in final form January 16, 1992.

Address correspondence and reprint requests to Dr. M.D. Ferrari, Department of Neurology, P.O. Box 9600, 2300 RC Leiden, The Netherlands. 
EME TC2-64B transcranial pulsed Doppler system (EME, Uberlingen, Germany). We used a hand-held 2$\mathrm{MHz}$ probe for the MCA and a $4-\mathrm{MHz}$ probe for the CCA, ECA, and ICA. Repeated measurements within each patient were obtained at an identical and vessel-specific depth. We determined both the systolic peak flow velocity $(\mathrm{cm} / \mathrm{sec})$ and the mean velocity $(\mathrm{cm} / \mathrm{sec})$ over a period of 5 seconds.

In addition, blood pressure (BP), heart rate, and respiratory frequency were measured.

Patients. We included patients with migraine with or without aura, ${ }^{13}$ aged 18 to 65 years. Demographic, clinical, and study characteristics of the patients are summarized in table 1 . Inclusion and exclusion criteria were the same as for the clinical trials..$^{3,12}$ In summary, all patients had a migraine history of at least 1 year with a maximum attack frequency of six per month, but were otherwise healthy. They notably had no cardiovascular diseases or hypertension $(\geq 160 / 95 \mathrm{~mm} \mathrm{Hg}$ ) and did not regularly use opiate analgesics, major tranquilizers, ergots ( $\geq 10 \mathrm{mg}$ per week), alcohol (315 g per week), or other drugs. In addition, patients had not used migraine prophylaxis within 2 weeks and ergot-containing preparations within 24 hours before the study treatment.

Only patients who presented with moderate (grade 2) or severe (grade 3 ) headache (on a 0 to 3 rating scale) were included, and they were divided into three treatment groups:

(1) Low-dose group: Thirty-six migraine patients who had participated in the first clinical trial and in whom BFV was measured 30 minutes after an sc injection of 3 $\mathrm{mg}$ sc sumatriptan; 18 of these patients had also received 1 or $2 \mathrm{mg}$ sc sumatriptan 30 minutes before the $3-\mathrm{mg}$ injection, ie, 60 minutes before the $\mathrm{BFV}$ measurement, without clinical improvement. ${ }^{12}$ In this group, the MCA was measured in all patients and the CCA, ECA, and ICA in twenty-five.

(2) High-dose group: Twenty migraine patients who had participated in the second trial and in whom BFV was measured 30 minutes after an sc injection of $6 \mathrm{mg}$ sumatriptan; 11 of them had received a first sc injection of $6 \mathrm{mg}$ sumatriptan 60 minutes before the second 6 -mg injection, ie, 90 minutes before the BFV measurement. ${ }^{3}$ All four vessels were measured in all of these patients.

(3) Placebo group: Eleven migraine patients who had participated in the first trial and had received placebo. ${ }^{12}$ The MCA was measured in all these patients and the CCA, ECA, and ICA in seven.

The study was approved by the local ethics committee, and patients gave written, informed consent.

Statistics. The effect of treatment on BFV in the different vessels was analyzed with repeated measurement ANOVA, split-plot type. The vessels (CCA, ECA, ICA, MCA) were all analyzed separately in each of the three treatment groups (low-dose, high-dose, and placebo). Subjects were crossed with the repeated factors "treatment" (pre- and post-treatment) and "side" (right or left). In the analysis of the low- and high-dose groups, subjects were also nested within the nonrepeated factor "subgroup dose" ( $3 \mathrm{mg}$ only or $3 \mathrm{mg}$ preceded by $1 \mathrm{mg}$ or $2 \mathrm{mg}$ in the low-dose group; $6 \mathrm{mg}$ or $6 \mathrm{mg}$ plus $6 \mathrm{mg}$ in the high-dose group).

Differences in sumatriptan-induced BFV changes at the headache and nonheadache sides were analyzed with repeated measurement ANOVA in the 47 subjects with unilateral headache. Subjects were crossed with the repeated factors "treatment" (pre- and post-treatment) and "headache side" (headache and nonheadache).
Table 1. Demographic and clinical characteristics of the study population

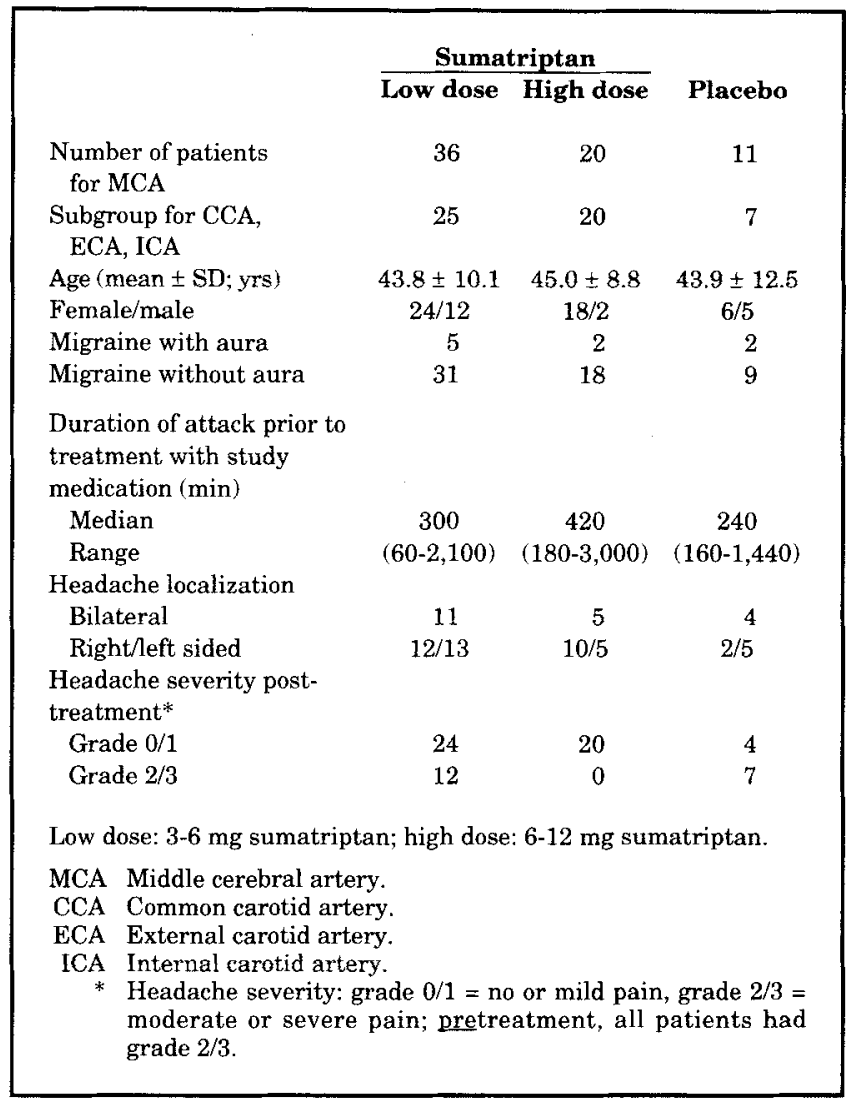

Differences in treatment effect between the three treatment groups were analyzed with one-way ANOVA and, when significant, followed by the Newman-Keuls range test for multiple comparisons. We believe that, although the data with high-and low-dose sumatriptan were obtained in two separate studies, comparison of these effects is allowed, because both clinical trials had a similar design and comparable patient population (table 1) and only differed with respect to the dosage of drug given.

Because of the multiple BFV measurements (four vessels and two parameters) per patient, the strict level of significance was set at $0.05 / 8=0.00625$ (Bonferroni's method).

Results. Clinical effect of sumatriptan. The clinical effect of treatment on headache severity at the time of BFV measurement is shown in table 1 . In the low-dose group, $24 / 36$ (66\%) of the patients had improved from severe or moderately severe headache to mild or no headache. In the high-dose group, 20/20 (100\%) had improved, and in the placebo group $4 / 11(36 \%)$. Clinical response rates differed significantly between the low- and highdose groups $\left(\chi^{2}, 8.5 ; p<0.005\right)$ and between the high-dose and placebo groups $\left(\chi^{2}, 16.4 ; p=0.0001\right)$. The difference between the low-dose and placebo groups was near significant $\left(\chi^{2}, 3.2 ; p=0.07\right)$, probably due to small numbers in the placebo group.

Vital signs. In none of the treatment groups was there a significant difference between measure- 
spontaneous migraine attacks. Both effects were clearly more pronounced with the higher doses of sumatriptan and appeared dose related. In contrast, after placebo treatment, neither the clinical condition nor the BFV were significantly different.

We investigated our patients in a double-blind, placebo-controlled design as part of two of the first clinical trials with sumatriptan. This experimental design has added considerable validity to the measurements, but the tight time schedule and the lack of knowledge about exactly what to expect both in terms of clinical improvement and changes in BFV may have introduced some potential confounding factors.

First, to create sufficiently large study groups, without including the same patients in more than one treatment group, we regrouped sumatriptantreated patients in two treatment groups. Thus, half of the patients in the low-dose group had already received $1 \mathrm{mg}$ or $2 \mathrm{mg}$ sumatriptan $30 \mathrm{~min}$ utes before the $3-\mathrm{mg}$ injection, ie, 60 minutes before the BFV measurement, and 11 of the 20 patients in the high-dose group had received a first sc injection with $6 \mathrm{mg}$ sumatriptan 60 minutes before the second $6-\mathrm{mg}$ injection, ie, 90 minutes before the investigation. However, in both cases, subgroup comparison between those patients who were investigated after two injections and those patients who were investigated after only one injection did not disclose significant differences in the final effect on the BFV. In fact, in both the low- and high-dose groups, the subgroup that received two doses even tended to show less increase in BFV than the subgroup that received only one dose. Further, $1 \mathrm{mg}$ and $2 \mathrm{mg}$ sumatriptan proved to be insufficient to cause a significant clinical improvement or change in BFV. We are therefore confident that grouping the patients in low- and high-dose treatment groups has not artefactually created nonexisting or greater differences.

A second potential confounding factor may have been the difference in time from treatment to investigation between the low-dose group ( $60 \mathrm{~min}$ utes to first injection, 30 minutes to final or single injection) and high-dose group (90 minutes to first injection, 30 minutes to final injection). We cannot exclude that this time difference may have contributed to the observed difference in BFV increase between high and low doses of sumatriptan, eg, secondary to a longer period of clinical improvement. However, both time frames are within the plasma half-life time of sumatriptan of about 2 hours. Furthermore, preliminary findings in 14 patients treated with $6 \mathrm{mg}$ sumatriptan during an attack-free period have shown a similar $25 \%$ increase in BFV, which was not further increased by a second $6 \mathrm{mg}$ sumatriptan injection 60 minutes later (in preparation). These observations would suggest that $6 \mathrm{mg}$ is an optimal dose in terms of increase of BFV. A 6-mg dose is optimal for clinical improvement, and a second 6 -mg dose does not cause additional improvement. ${ }^{3}$
Third, we could not reliably measure $\mathrm{PCO}_{2}$. Sumatriptan-induced changes in $\mathrm{PCO}_{2}$ could have affected BFV. Although we cannot exclude this possibility, we believe that $\mathrm{PCO}_{2}$ was not greatly changed by sumatriptan; there are no pharmacologic clues to expect such a mechanism, and the respiration rate was not significantly altered. In addition, Friberg et al $^{14}$ failed to demonstrate a significant change in end-tidal $\mathrm{PCO}_{2}$ after treatment with sumatriptan.

Blood flow through a vessel is positively related to the $\mathrm{BFV}$ and inversely related to the cross-sectional area of the vessel. An increase in BFV therefore suggests either a constriction of the investigated vessel, an increase in the total blood flow through that vessel, or a combination of both mechanisms. Admittedly, we cannot determine the precise mechanism of the sumatriptan-induced increase in BFV since we have not measured the cross-sectional area and blood flow. However, in animal experiments, sumatriptan decreases (and certainly not increases) total carotid blood flow and increases carotid vascular resistance..$^{4,6}$ One would expect these effects to have decreased BFV, thus obscuring any increase in BFV. Notwithstanding, we observed a clear increase in BFV. Further, infusion of 5-HT causes a marked constriction of the ICA in baboons, without affecting rCBF. ${ }^{15}$ Finally, Friberg et $\mathrm{al}^{14}$ recently found no change in $\mathrm{rCBF}$ in the MCA supply territory after an intravenous infusion of $2 \mathrm{mg}$ sumatriptan, sufficient to increase $\mathrm{BFV}$ in the MCA. Therefore, the increase in BFV is probably due to constriction of the ICA and MCA. This is compatible with the in vitro findings that sumatriptan constricts human cerebral arteries, ${ }^{16,17}$ but is unexpected in view of human in vivo studies suggesting vasoconstriction in the external carotid artery bed to be the main effect of 5-HT and ergotamine. ${ }^{18}$ Since sumatriptan is highly selective for $5-\mathrm{HT}_{1 \mathrm{~d}}$ receptors, ${ }^{1,2}$ our data also suggest that 5$\mathrm{HT}_{1 \mathrm{~d}}$ receptors occur on the ICA and $\mathrm{MCA}$ and are functionally important.

After we began our study, there were two published reports on the effects of sumatriptan on BFV. ${ }^{14,19}$ Friberg et al ${ }^{14}$ investigated seven patients in an open study and found a selective effect of sumatriptan on the MCA at the headache side only and only during the attack but not during the attack-free period. ${ }^{14}$ Because rCBF was not changed, they concluded that sumatriptan acts predominantly on pathologically distended arteries. In contrast, in a much larger and controlled study, we found no differences between the headache and nonheadache sides. We also have found an increase in $\mathrm{BFV}$ during the attack-free period (in preparation). These discrepancies may be related to four of their patients being investigated during a migraine attack with aura, known to be associated with asymmetric rCBF changes. ${ }^{20}$ In contrast, our patients were investigated during predominantly migraine attacks without aura (table 1 ). In addition, Friberg et al used only $2 \mathrm{mg}$ sumatriptan IV 
(which corresponds to about $2 \mathrm{mg} \mathrm{sc}$ ) and did BFV measurements after ${ }^{133} \mathrm{Xe}$ rCBF measurements, which in itself may increase BFV. ${ }^{21}$ Diener et al ${ }^{19}$ investigated BFV after $4 \mathrm{mg}$ sc sumatriptan in the MCA and basilar artery of six patients during the withdrawal phase from ergotamine-induced headache. Despite transient clinical improvement, there was no significant change in BFV. In our study, $3 \mathrm{mg}$ se sumatriptan was sufficient to increase $\mathrm{BFV}$ in normal migraine attacks. The lack of change in BFV in the study of Diener et al may have been related either to the small number of patients or to a counteracting action in ergotaminedependent patients. This would suggest that the clinical effect of sumatriptan in treating ergotamine-withdrawal symptoms may be independent of its vasoconstrictor action. ${ }^{7}$

We conclude that increasing sc doses of sumatriptan up to $6 \mathrm{mg}$ cause both a greater increase in BFV in the MCA and ICA, presumably due to vasoconstriction, and a higher proportion of improved patients. Thus, $5-\mathrm{HT}_{1 \mathrm{~d}}$-receptor-mediated vasoconstriction of the large basal arteries of the circle of Willis and the clinical efficacy of sumatriptan in the treatment of migraine attacks appear to be related. Our data, however, do not permit the conclusion that the two factors are causally related.

\section{Acknowledgments}

We would like to thank A.H. Zwinderman, Msc, Department of Medical Statistics, for statistical advice, and the Dutch Migraine Foundation, Glaxo Group Research, Greenford, UK, and Glaxo $\mathrm{BV}$, Nieuwegein, NL, for financial support.

\section{References}

1. Humphrey PPA, Perrin MJ, Feniuk W, Oxford AW. The pharmacology of the novel 5 - $\mathrm{HT}_{1}$-like receptor agonist GR43175. Cephalalgia 1989;9(suppl 9):23-33.

2. Deliganis AV, Peroutka SJ. 5-Hydroxytryptamine 1 receptor agonism predicts antimigraine efficacy. Headache 1991;31:228-231.

3. Ferrari MD, Melamed E, Gawel MJ, et al. Treatment of migraine attacks with sumatriptan. N Engl J Med 1991;325:316-321.

4. Perrin MJ, Feniuk W, Humphrey PPA. The selective closure of feline carotid arteriovenous anastomoses (AVAs) by
GR43175. Cephalalgia 1989;9(suppl 9):41-46.

5. Saxena PR, Ferrari MD. 5-HT - -like receptor agonists and the pathophysiology of migraine. Trends Pharmacol Sci 1989;10:200-204.

6. Den Boer MO, Villalon CM, Heiligers JPC, Humphrey PPA, Saxena PR. Role of $5-\mathrm{HT}_{1}$-like receptors in the reduction of porcine cranial arteriovenous anastomotic shunting by sumatriptan. Br J Pharmacol 1991;102:323-330.

7. Buzzi MG, Moskowitz MA. The antimigraine drug sumatriptan (GR 43175) specifically blocks neurogenic plasma extravasation from blood vessels in dura mater. Br J Pharmacol 1990;99:202-206.

8. Heyck H. Pathogenesis of migraine. Res Clin Stud Headache 1969;2:1-28.

9. Saxena PR. Is there still a case for the shunt hypothesis in migraine? In: Sandler M, Collins G, eds. Migraine: a spectrum of ideas. Oxford: Oxford Medical Publ, 1990:191-197.

10. Moskowitz MA. Basic mechanisms in vascular headache. Neurol Clin 1990;8:801-815.

11. Aaslid R, ed. Transcranial Doppler sonography. Vienna: Springer Verlag, 1986.

12. Ferrari MD, Bayliss EM, Ludlow S, Pelgrim AJ. Subcutaneous GR43175 in the treatment of acute migraine: an international study. Cephalalgia 1989;9(suppl 10):348349.

13. Headache Classification Committee of the International Headache Society: classification and diagnostic criteria for headache disorders, cranial neuralgias and facial pain. Cephalalgia 1988;7(suppl 8):1-96.

14. Friberg L, Olesen J, Iversen HK, Sperling B. Migraine pain associated with middle cerebral artery dilation: reversal by sumatriptan. Lancet 1991;338:13-17.

15. Harper AM, MacKenzie ET. Cerebral circulation and metabolic effects of 5-hydroxytryptamine in anaesthesized baboons. J Physiol (Lond) 1977;271:721-733.

16. Parsons AA, Whalley ET. Characterization of the 5-hydroxytryptamine receptor which mediates contraction of the human isolated basilar artery. Cephalalgia 1989;9(suppl 9):47-51.

17. Hamel E, Bouchard D. Contractile $5-\mathrm{HT}_{1 \mathrm{~d}}$ receptors in human brain vessels. In: Fozard JR, Saxena PR, eds. Serotonin: molecular biology, receptors and functional effects. Basel: Birkhauser Verlag, 1991:264-274.

18. Puzich R, Girke W, Heidrich H, Rischke M. Assessment of extracranial cerebral vessels in patients with migraine after administration of ergotamine tartrate using Doppler ultrasound. Dtsch Med Wochenschr 1983;108:457-461.

19. Diener HC, Peters C, Rudzio M, et al. Ergotamine, flunarizine and sumatriptan do not change cerebral blood flow velocity in normal subjects and migraineurs. J Neurol 1991;238:245-250.

20. Olesen J, Friberg L, Skyhoi Olsen T, et al. Timing and topography of cerebral blood flow, aura and headache during migraine attacks. Ann Neurol 1990;28:791-798.

21. Russell D, Dahl A, Nyberg-Hansen R, Rootwelt K. Reproducibility of simultaneous TCD and rCBF measurements. Cephalalgia 1991;11(suppl 11):46. 


\section{Neurology}

\section{Antimigraine drug sumatriptan increases blood flow velocity in large cerebral arteries during migraine attacks}

J.F.V. Caekebeke, M. D. Ferrari, C. P. Zwetsloot, et al.

Neurology 1992;42;1522

DOI 10.1212/WNL.42.8.1522

\section{This information is current as of August 1, 1992}

Updated Information \&

Services

Citations

Permissions \& Licensing

Reprints including high resolution figures, can be found at:

http://n.neurology.org/content/42/8/1522.full

This article has been cited by 1 HighWire-hosted articles: http://n.neurology.org/content/42/8/1522.full\#\#otherarticles

Information about reproducing this article in parts (figures,tables) or in its entirety can be found online at:

http://www.neurology.org/about/about_the_journal\#permissions

Information about ordering reprints can be found online:

http://n.neurology.org/subscribers/advertise

Neurology $®$ is the official journal of the American Academy of Neurology. Published continuously since 1951, it is now a weekly with 48 issues per year. Copyright (@) 1992 by the American Academy of Neurology. All rights reserved. Print ISSN: 0028-3878. Online ISSN: 1526-632X.

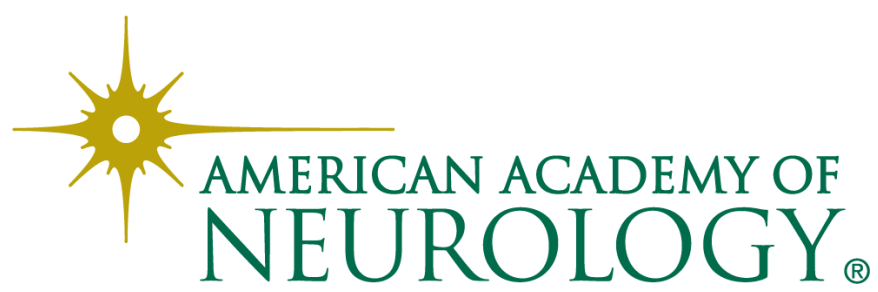

